American Journal of

Health, Medicine and Nursing Practice (AJHMN)

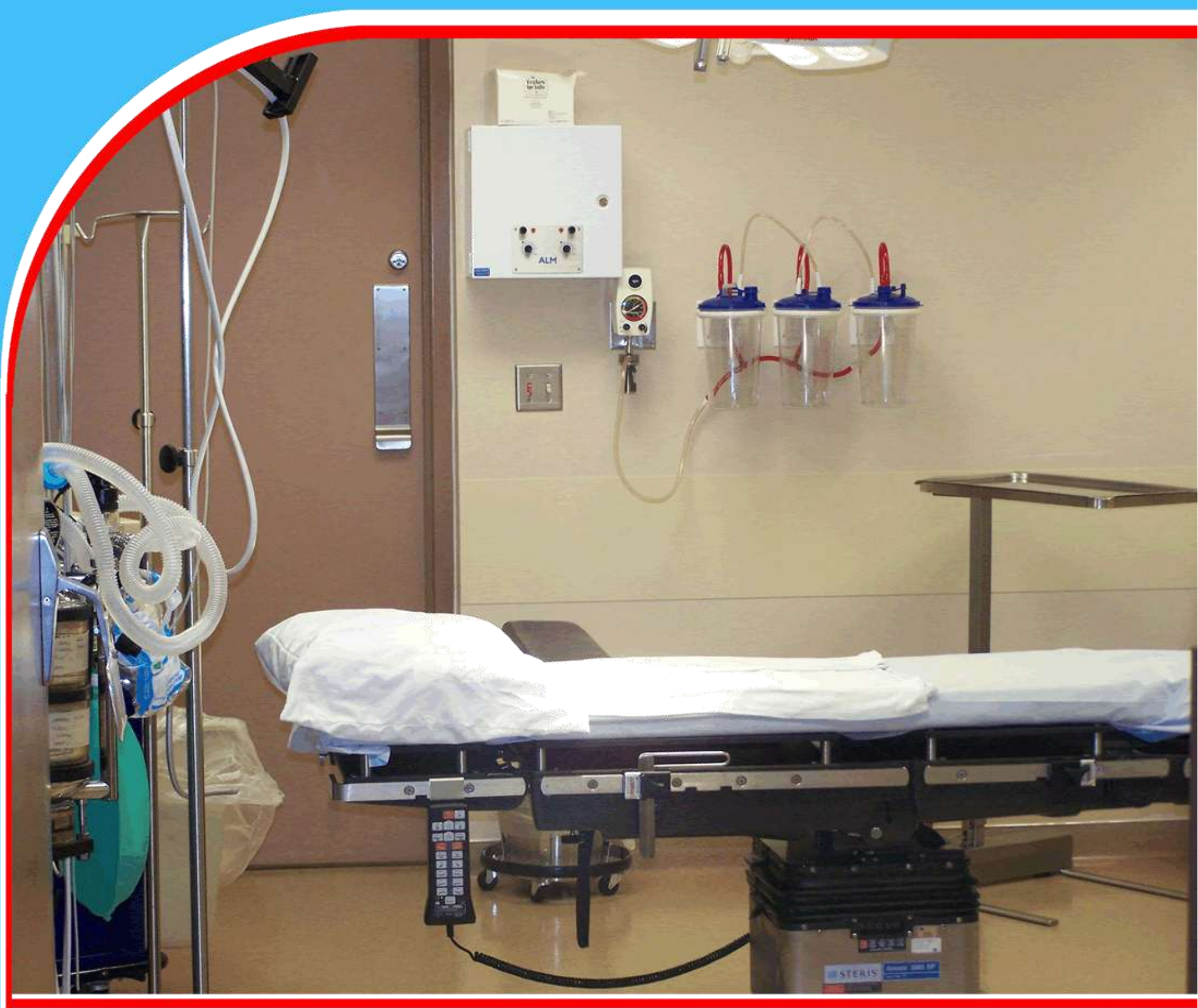

KNOWLEDGE, ATTITUDE AND PRACTICE REGARDING EPILEPSY AMONG NURSES IN ASUTIFI NORTH DISTRICT

Richard Opoku Asare Akwasi Boakye-Yiadom

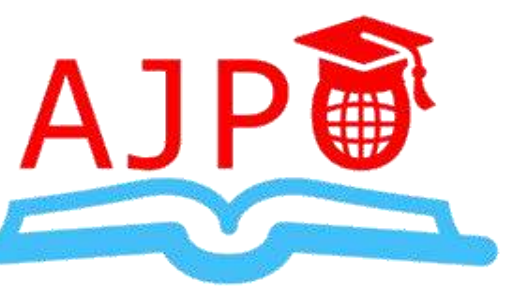




\title{
KNOWLEDGE, ATTITUDE AND PRACTICE REGARDING EPILEPSY AMONG NURSES IN ASUTIFI NORTH DISTRICT
}

\author{
Richard Opoku Asare ${ }^{1}$ \\ MPhil, BEd, RN (Dip)-RMN, Cert.Ed. \\ College of Nursing, Ntotroso \\ Corresponding Author's Email: asareor@gmail.com
}

Akwasi Boakye-Yiadom ${ }^{2}$

MSc, B.Ed

Department of Public Health, School of Allied Health Sciences, UDS, Tamale, Ghana

Paul Armah Aryee ${ }^{3}$

$\mathrm{PhD}$, MPhil, MMEdSc, BSc

Department of Public Health, School of Allied Health Sciences, UDS, Tamale, Ghana

\begin{abstract}
Purpose: To assess the knowledge, attitude and practice regarding epilepsy among nurses within the Asutifi North District with the aim of understanding their subjective experiences and knowledge on epilepsy in a sociocultural context and how their attitude shape their practice towards people with epilepsy.

Methodology: The study employed an exploratory descriptive cross-sectional design. The study population consisted of nurses who have been licensed by the Nursing and Midwifery Council of Ghana and working in government facilities. The exclusion criteria were private health facilities, non-trained health professionals and other health professionals without nursing background, and student nurses on clinical attachment during the period of study in the district. Multistage sampling technique was used to select the study participants from the communities. A standard statistical formula was used to arrive at a sample size of 102. Data was collected by using a semi-structured questionnaire. Descriptive statistics involving frequencies and percentages were used in representing data. Responses on other items were cross-tabulated. The statistical tool that was used for analyzing the data was by STATA version 12 .

Results: Findings showed that $67.7 \%$ (69/102) of the nurses were aware of the causes of epilepsy, 59.8\% have low level of knowledge on the disease. Though $82.4 \%$ of the nurses suspect people with epilepsy to have mental illness, $70.6 \%$ of the nurses had positive attitude towards epilepsy. However, 52.9\% exhibited poor practices towards the disease. The socio-demographic characteristics of religion (Muslim) $(\mathrm{p}=0.017)$, area of specialty $(\mathrm{RMN})(\mathrm{p}=0.045)$ as well as close family relationship with epilepsy $(\mathrm{p}=0.001)$ were significantly associated with knowledge on epilepsy. Factors that were found to influence attitude towards epilepsy were sex (Female) $(\mathrm{p}=0.037)$, religion (Muslim) $(\mathrm{p}=0.012)$ and specialty area $(\mathrm{RMN})(\mathrm{p}=0.054)$. The area of specialty statistically influences their practices on epilepsy $(\mathrm{p}=0.001)$. There was no statistically significant association between knowledge on epilepsy and practice $(\mathrm{p}=0.134)$. However, attitude significantly related to practices on epilepsy $(\mathrm{p}=0.008)$ and indicated that negative attitude was more likely to be associated with poor practice.

Conclusion: Nurses at the Asutifi North District tended to have low knowledge, positive attitude and poor practices on epilepsy.

Recommendation: The Ghana Health Service in collaboration with the Ministry of Health should run intermediary workshops, at least every six months, to train nurses in epilepsy diagnoses to reduce the treatment gap. The health directorate should raise awareness and educate the communities on epilepsy to reduce stigma. Enhancing nursing education and training on epilepsy by the Ministry of Health and its agencies is imperative to improving health care delivery for people living with the disease.
\end{abstract}

Key words: Knowledge, Attitude, Practice, Epilepsy, Asutifi North District 


\section{INTRODUCTION}

Epilepsy and psychiatry have historical links. The three ancient Indian medical systems of Siddha, Ayurveda (Science of life), and Unani all recognized epilepsy [1]. Epilepsy comes from the Greek word "epilambanein", which means to be attacked or to be seized [2,3]. In the Arabic language, the term used for epilepsy is called "Al-Saraa". The Arab and Muslim scientists like Al-Tabari and Al-Razi also described epilepsy in their books, thousand years ago, as a disease of the brain, making a clear distinction between it and the psychiatric disorders, by stating clearly that epilepsy is not related to evil spirits or supernatural powers [2].

Epilepsy is one of the world's oldest known brain disorders among several medical conditions $[4,5]$. It is the second most commonly seen neurological condition in primary care, and the most commonly seen among neurologists [13]. A recent study has indicated that 70 million people are estimated to suffer from this disease [3]. Persons with epilepsy are at risk of developing a variety of psychological problems including depression, anxiety and psychosis [6,7]. Because epileptic seizures typically include convulsions, the term convulsion is sometimes used as a synonym for seizure. However, not all epileptic seizures lead to convulsions, and not all convulsions are caused by epileptic seizures. The word "fit" is sometimes used to mean a convulsion or epileptic seizure [8]. Epilepsy as one of the major brain disorders worldwide and should be considered a health care priority in Africa. It is triggered by abnormal electrical activity in the brain resulting in an involuntary change in body movement, function, sensation, awareness and behaviour. The condition is characterized by repeated seizures or "fits" as they are commonly called. These take many forms ranging from the shortest lapse of attention to severe and frequent convulsions. Epilepsy is not only a medical condition; it also includes sociological, economical, and cultural dimensions. [9] Unlike other neurological conditions, epilepsy can be completely controlled in the majority of cases by medication or surgical procedures [13] as most of the causes of symptomatic epilepsy are preventable and treatable [9].

In spite of global advances in diagnosis and treatment in recent years, about eight million people with epilepsy (PWE) in Africa are not treated with modern anti-epileptic drugs [9]. It is also estimated that 80 percent of the burden of epilepsy is in the developing world, where in some areas 80 to 90 percent of people with epilepsy receive no treatment at all [10]. Many individuals with epilepsy are perceived by the community as weak, inhuman, dangerous or inferior because of their symptoms, and as result of the stigma, these people are excluded. But epilepsy is treatable and up to 70 percent of the seizure can be cured and the risk of reoccurrence is about 25 percent" [11]. Despite the fact that highly effective, low-cost treatments are available, as many as 9 of 10 people with epilepsy in Africa go untreated. The reasons for the unavailability of treatment include: inadequate health delivery systems, lack of trained personnel, lack of essential drugs, and traditional beliefs and practices that often do not consider epilepsy as a treatable condition. This treatment gap greatly increases the burden of epilepsy and disability [12].

Because there is public fear and misunderstanding about the disorder, it makes many people unwilling to talk about it. The unwillingness leads to lives lived in the shadows, discrimination in workplace and communities, and a lack of funding for new therapies research [5]. This is evident in a report that literate adults in urban population of Ghana are ignorant of the cause of epilepsy. When quizzed, 172 (45.3\%) out of the 380 respondents did not know the cause of epilepsy. Out of 
the 358 responses to the cause of epilepsy, 114 (31.8\%) said it was inherited disease, $100(27.9 \%)$ said it was due to witchcraft/juju or spiritual [14]. A similar study conducted on beliefs on epilepsy in Northern Ghana highlighted that the most interesting perceived cause of seizures in males is habouring anal worms, and spirituality a strong notion as a perceived cause. Besides, there is the belief that spells of epilepsy are cast on women as a form of punishment when they engage in adultery [16]. It is worth noting that when someone has seizure does not necessarily mean that person has epilepsy, though. Certain things can sometimes trigger seizures in people with epilepsy. They include: Flashing or bright lights; A lack of sleep; Overstimulation (like staring at a computer screen or playing video games for too long); certain medications; and Hyperventilation (breathing too fast or too deeply). In addition, seizures can be triggered in anyone under certain conditions, such as life-threatening dehydration or high temperature. But when a person experiences repeated seizures for no obvious reason, that person is said to have epilepsy [39]. It is therefore important to make behavioural and psychosocial adjustments with epileptic patients to control seizure and improve and attain higher quality of life by sticking to medication regimen, having adequate sleep, good nutrition and reducing stress [40].

In connection with the manifestations of epilepsy, the disease is also referred to as saturation of the foams in the stomach which overflow and rise to the head, resulting in a seizure [18]. However, the most common symptoms proffered by most respondents as manifestations of epilepsy include convulsion, falling down, rolling of eyes, foaming of mouth, urination, and biting of tongue [7,19]. Interestingly, surveys in developing countries with different cultures reveal common beliefs, for example, that epilepsy is a contagious illness or a kind of mental retardation [20]. Although a lot of misconceptions about epilepsy exist, it is reported that epilepsy can be spread by contact and that epileptics must be isolated or avoided [14]. This assertion was supported in a study among people with epilepsy that indicated $2.2 \%$ of the respondents admitted that epilepsy is transmitted through contacts with epileptic patients [21].

The attitude of a person towards a certain object (person, word, or behavior) can be defined as a subjective evaluation of this object. The subjective value of an object can be negative, neutral or positive [24,25]. Though attitude is a complex and abstract construct [26], people suffering from epilepsy have been discriminated against in several ways [27]. Report from other studies have shown that people with less awareness and knowledge about epilepsy tend to have negative attitudes toward the disease and misperceptions such as epilepsy being a form of insanity, untreatable, contagious, and hereditary or a form of mental retardation. Cultural beliefs, superstition, and lack of information about epilepsy have perpetuated such misconceptions in developing countries [28]

In terms of practice on epilepsy, report indicates that about $90 \%$ of patients with epilepsy are not under hospital supervision at any one time; for that matter the role of the general practitioner in the care of these individuals is important. There is no doubt that community care of people with epilepsy needs much improvement [31]. Nurses are professionals who play a very important role in providing coordinated care and education to patient with epilepsy. Since people with epilepsy receive treatment from primary care providers rather than neurologists, an understanding of the diagnosis and treatment provide optimal patient care. This is evident by the statement that out of 127 patients who were randomized to a nurse run clinic, $106(83 \%)$ attended the clinic. This was 
attributed to the fact that the nurse was able to identify possible improvements in the drug management of over a fifth of the patients she saw [33]. Consequently, a study to test patients with uncontrolled epilepsy has shown that one hundred fourteen adults with epilepsy have a significant effect in quality of life of patient with epilepsy due to nurse-led intervention programs which include dissemination of accurate information to the clients, performing epilepsy audit towards creation of a profile of epilepsy in general practice to improve care, and devising treatment plans and goals [32]. Therefore, nursing care for patients with epilepsy is a very important issue because such patients are exposed to many risks and complications. Nurses must take special care to decrease the risk. The most important nursing intervention is to keep up an adequate airway, breathing and circulation during seizures and to prevent any injury of the patients with epilepsy. Also, an oral airway suction apparatus should be available at bedside at all times [34] to reduce danger whiles optimizing results in the management of the patient [35].

In line with whether epilepsy is treatable or not, approximately one-third of clinical nurses $(36.5 \%)$ believed that epilepsy was incurable [30]. This notion is strongly perpetuated by the statement that some epilepsy cases cannot be cured [36], and a study claimed that epilepsy cannot be cured with medication arguing that about 3 in 10 people experienced seizures, despite medication [37]. It was therefore concluded that when seizures persist beyond a certain age, families and health care personnel placed child in the "sickness sphere," meaning that the child is incurable and treatment attempts are futile [38]. However, a survey indicated that $79 \%$ of nurses are of the view that epilepsy can be controlled or cured in this case $25 \%$ of the nurses. Regarding the aim of treatment of epilepsy, it is highlighted that $60 \%$ of respondents claimed that medications decrease the frequency of seizures, and $36.6 \%$ opined that epilepsy could wholly be cured [21]. A reported on the possibility of treatment of epilepsy, both basic $(72.73 \%)$ and clinical $(86.49 \%)$ medical students were of the view that epilepsy can be treated. They share the view that the disease can be treated in the hospital as indicated by $68.60 \%$ of the basic medical students and $87.39 \%$ by the clinical students [17].

An observation made between October and November 2016 at the Asutifi North District Health Directorate in Brong Ahafo Region of Ghana indicated that among the top 10 diseases in the district, epilepsy was not captured, and that the district has minimal information on epilepsy. This was evident by data gathered from the Ghana Health Service (GHS) District Health Information Management System (DHIMS) which indicated that the Brong Ahafo Region had recorded 17,666 for cases of epilepsy in 2012, with 104 cases of epilepsy for Asutifi South District, but none for the Asutifi North. In 2013, there was a rise in reported cases of the condition up to 1,888, but a slight decline in Asutifi South with reported cases being 100. In 2014 and 2015, the number of reported cases increased to 3,166 and 3,495 respectively, whilst the Asutifi South recorded 128 and 125 within the same period, but none for the Asutifi North Health Directorate. However, there was a sharp fall in the reported cases of epilepsy in the Region with a figure of 1,377 with the Asutifi North Health Directorate recording 10 cases from January to June, 2016, and in the same duration Asutifi South recorded 33 cases [15]. 
Despite the increase education and health care, some health professionals continue to linger in darkness about cause and treatment options of the disease. As efforts to improve care of people living with epilepsy are a major concern, little has been done to identify the extent of subjective knowledge, attitude and practice among nurses.

\section{METHODOLOGY}

This was a an exploratory cross sectional study on knowledge, attitude and practice of nurses in epilepsy working in the Asutifi North District in the Brong Ahafo Region of Ghana. The study population consisted of nurses (both males and females) who have been licensed by the Nursing and Midwifery Council of Ghana and working in government facilities. The exclusion criteria were private health facilities, non-trained health professionals and other health professionals without nursing background, and student nurses on clinical attachment during the period of study in the district.

Multistage sampling technique was used to select the study participants from the communities. A standard statistical formula from Rumsey, 2016, was used to arrive at a sample size of 102. The starting point was randomly selected and a systematic random sampling method was used to select the study participants.

The research tool used for data collection for this study was a semi-structured questionnaire.

Descriptive statistics, which involves frequencies and percentages, were used in representing data for the socio-demographic characteristics of all respondents. Besides, responses on other items and other relevant questions were cross-tabulated. The statistical tool that was used for analyzing the data was statistics and data, syllabic abbreviated as STATA, version 12.

A bivariate logistic regression analysis was conducted to test the association between independent variables and outcome variables. In responding to the questionnaire, participants who demonstrated positive responses on multiple options were operationally categorized into high knowledge and those with poor responses as having low knowledge of the disease under study. This was done to see how significant the variables influence the outcomes of the study. This was also done for attitude and practices on epilepsy as having positive and negative attitude and practice respectively on their categorizations.

\section{RESULTS}

\section{Socio-demographic characteristics}

The response rate was $100 \%$. Majority of the nurses $80(78.43 \%)$ were between the ages 21 and 30 years. More than half $75(73.5 \%)$ were females. Concerning religion, $89(87.3 \%)$ were Christians, eight (7.8\%) Muslims and four (3.9\%) practiced African Traditional Religion, with only one (1.0\%) belonging to Buddhism. About 40 (39.2\%) were Community Health Nurses, while seven (6.9\%) were Registered Midwives, and 29 (28.4\%) were Health Assistant Clinical (HAC). About nine $(8.8 \%)$ had a close family member with a history of epilepsy. Table 1 depicts the sociodemographic data of the respondents. 
American Journal of Health, Medicine and Nursing Practice

ISSN 2520-4017 (Online)

Vol.5, Issue 1 No.4, pp 43 - 65, 2020

www.ajpojournals.org

Table 1: Socio-demographic Data of Respondents

\begin{tabular}{|c|c|c|}
\hline Variable & $\begin{array}{c}\text { Frequency } \\
\text { (102) }\end{array}$ & $\begin{array}{c}\text { Percentage } \\
(100 \%)\end{array}$ \\
\hline \multicolumn{3}{|l|}{ Age } \\
\hline - $21-30$ & 80 & 78.43 \\
\hline$-\quad 31-40$ & 14 & 13.73 \\
\hline$-41-50$ & 5 & 4.90 \\
\hline$-51-60$ & 3 & 2.94 \\
\hline \multicolumn{3}{|l|}{ Sex } \\
\hline - Male & 27 & 26.5 \\
\hline - Female & 75 & 73.5 \\
\hline \multicolumn{3}{|l|}{ Religion } \\
\hline - Christianity & 89 & 87.3 \\
\hline - Muslim & 8 & 7.8 \\
\hline - African Traditional & 4 & 3.9 \\
\hline - Others & 1 & 1.0 \\
\hline \multicolumn{3}{|l|}{ Specialized Area } \\
\hline - $\quad$ RGN & 15 & 14.7 \\
\hline - $\quad \mathrm{RMN}$ & 11 & 10.8 \\
\hline - $\quad \mathrm{RM}$ & 7 & 6.9 \\
\hline$-\mathrm{CHN}$ & 40 & 39.2 \\
\hline - Others & 29 & 28.4 \\
\hline \multicolumn{3}{|l|}{ Close Family with Epilepsy } \\
\hline - Yes & 9 & 8.8 \\
\hline$-\quad$ No & 93 & 91.2 \\
\hline
\end{tabular}

Source: Field data (2017)

\section{Knowledge of factors contributing to the development of epilepsy}

Table 2 below shows the result of respondents' knowledge on factors contributing to the development of epilepsy. The results of the perceived causes of epilepsy showed that $48.0 \%$ of the nurses associated birth trauma to be the cause of epilepsy which is correct response. In terms of hereditary, $22.5 \%$ of the respondent gave their accent to it which is a wrong response, whilst $13.7 \%$ of the respondents attributed the onset of the disease to brain injury which they were right. Though the same number of the nurses indicated witchcraft as the perceived cause of epilepsy, they were wrong with that notion. Notwithstanding the perceived causes of epilepsy, the result of the data indicated that $57.8 \%$ of the respondents agreed that convulsion contribute to the development of epilepsy, $21.6 \%$ of the respondents agreed that high body temperature contribute to the development of epilepsy whilst $14.7 \%$ of the respondents concurred malaria as a contributing factor to the development of epilepsy. It is worth noting that all those responses given by the nurses were all correct. In connection with maternal factors, the result showed that $68.6 \%$ of the respondents agreed that maternal alcohol consumption is a risk factor in epilepsy, $64.7 \%$ of the respondents agreed that malnutrition is a risk factor in epilepsy, $49.0 \%$ of the respondents were in accord that drug use is a risk factor in epilepsy, while only a few $23.6 \%$ of the nurses knew maternal 
age above 30 years to be a risk factor for developing epilepsy. The above responses given by the nurses on the maternal risk factors to the development of epilepsy were all right.

Critical assessment of the maternal risk factors led to the ascertainment of some activities that sometimes trigger seizure in people with epilepsy. Out of the 102 respondents, $8.8 \%$ nurses said "Yes" staring at TV/Computer screen for too long could trigger seizure. Besides, 36.3\% of the nurses cited Stress as a triggering factor. In terms of breathing too fast/deeply could trigger seizure in PWE, 3.9\% of the nurses accented to that fact. More so, $12.7 \%$ of the nurses claimed Flashing or bright light could trigger seizure, $45.1 \%$ of them identified lack of sleep as a contributory factor that could trigger seizure in PWE. The responses given by the few nurses on this variable were all correct.

Data collected on the manifestation of epilepsy from the nurses depicted that out of the 102 respondents, 31.4\% of the nurses said "Yes" to Shrill cry (Shouting) as a clinical feature of epilepsy. In addition, $49.0 \%$ of the respondents indicated positive to loss of consciousness. Whilst falling down was accepted by $48.0 \%$ nurses as a manifestation of epilepsy, majority $60.8 \%$ of the nurses claimed jerking of the body as the cardinal manifestation of epilepsy, and Rolling of the eyes was accepted by $30.4 \%$ of the nurses, and $45.1 \%$ of the respondents said "Yes" to foaming of the mouth. When it came to the biting of the tongue as a manifestation of epilepsy, $30.4 \%$ (31/102) of the nurses affirmed it as a clinical feature; urination was mentioned by $23.5 \%$ of the respondents. Few $15.7 \%$ of the nurses responded "Yes" to abnormal behaviour as a manifestation. A critical assessment of the findings on manifestations of epilepsy from the respondents depicted that the responses afore-given were all right. It was deduced from the data that majority of the nurses do not know the clinical features of the disease. This is evident from the negative responses cited by the majority of the respondents. However, the manifestations serve as indicators in monitoring people with epilepsy so that urgent or immediate attention could be given to PWE. 
American Journal of Health, Medicine and Nursing Practice

ISSN 2520-4017 (Online)

Vol.5, Issue 1 No.4, pp 43 - 65, 2020

www.ajpojournals.org

Table 2: Knowledge of respondents on factors contributing to the development of epilepsy

\begin{tabular}{|c|c|c|}
\hline \multirow{2}{*}{$\begin{array}{l}\text { Factors contributing to the Development of } \\
\text { Epilepsy }\end{array}$} & \multicolumn{2}{|c|}{ Response rate $(\mathrm{N}=102)$} \\
\hline & Correct (\%) & Wrong (\%) \\
\hline \multicolumn{3}{|l|}{ Perceived causal factors } \\
\hline - $\quad$ Curse & $95(93.1 \%)$ & $7(6.9 \%)$ \\
\hline - $\quad$ Hereditary & $79(77.5 \%)$ & $23(22.5 \%)$ \\
\hline - Brain injury & $14(13.7 \%)$ & $88(86.3 \%)$ \\
\hline - Witchcraft & $88(86.3 \%)$ & $14(13.7 \%)$ \\
\hline - $\quad$ Birth trauma & $49(48.0 \%)$ & $53(52.0 \%)$ \\
\hline - $\quad$ Spiritually possessed & $90(88.2 \%)$ & $12(11.8 \%)$ \\
\hline - Brain infection & $10(9.8 \%)$ & $92(90.2 \%)$ \\
\hline - $\quad$ Poison/Bad blood & $96(94.1 \%)$ & $6(5.9 \%)$ \\
\hline \multicolumn{3}{|l|}{ Personal factors } \\
\hline - Convulsion & $59(57.8 \%)$ & $43(42.2 \%)$ \\
\hline - $\quad$ High temperature & $22(21.6 \%)$ & $80(78.4 \%)$ \\
\hline - Malaria & $15(14.7 \%)$ & $87(85.3 \%)$ \\
\hline - Parasitic infections & $9(8.8 \%)$ & $93(91.2 \%)$ \\
\hline - $\quad$ Others factors & $4(3.9 \%)$ & $98(96.1 \%)$ \\
\hline \multicolumn{3}{|l|}{ Maternal factors in epilepsy } \\
\hline - $\quad$ Maternal alcohol & $70(68.6 \%)$ & $32(31.4 \%)$ \\
\hline - Malnutrition & $66(64.7 \%)$ & $36(35.3 \%)$ \\
\hline - $\quad$ Drug use & $50(49.0 \%)$ & $52(52.0 \%)$ \\
\hline - $\quad$ Maternal age $>30$ years & $24(23.6 \%)$ & $78(76.4 \%)$ \\
\hline \multicolumn{3}{|l|}{ Triggering factors } \\
\hline - $\quad$ Lack of sleep & $46(45.1 \%)$ & $56(54.9 \%)$ \\
\hline - $\quad$ Stress & $37(36.3 \%)$ & $65(63.7 \%)$ \\
\hline - $\quad$ Flashing/Bright light & $13(12.7 \%)$ & $89(87.3 \%)$ \\
\hline - $\quad$ Staring at screen for long & $9(8.8 \%)$ & $93(91.2 \%)$ \\
\hline - $\quad$ Breathing too fast & $4(3.9 \%)$ & $98(96.1 \%)$ \\
\hline \multicolumn{3}{|l|}{ Manifestation of Epilepsy } \\
\hline - Jerking of the body & $62(60.8 \%)$ & $40(39.2 \%)$ \\
\hline - Loss of consciousness & $50(49.0 \%)$ & $52(51.0 \%)$ \\
\hline - Falling down & $49(48.0 \%)$ & $53(52.0 \%)$ \\
\hline - Foaming of the mouth & $46(45.1 \%)$ & $56(54.9 \%)$ \\
\hline - Shrill cry (Shouting) & $32(31.4 \%)$ & $70(68.6 \%)$ \\
\hline - Rolling of the eye & $31(30.4 \%)$ & $71(69.6 \%)$ \\
\hline - Biting of tongue & $31(30.4 \%)$ & $71(69.6 \%)$ \\
\hline - Urination & $24(23.5 \%)$ & $78(76.5 \%)$ \\
\hline - Abnormal behaviour & $16(15.7 \%)$ & $86(84.3 \%)$ \\
\hline
\end{tabular}

Source: Field data (2017) 


\section{Categorization of level of knowledge on epilepsy}

Participants who scored 16 correct or more out of the 31 items on the knowledge of factors contributing to the development of epilepsy were operationally labelled as having "high" knowledge and those who scored less or equal to 15 seen as having "low" knowledge. This is shown in table 3 below.

Table 3: Level of knowledge of participants

\begin{tabular}{cccc}
\hline Level of knowledge & $\begin{array}{c}\text { Frequency } \\
(\mathbf{N = 1 0 2})\end{array}$ & $\begin{array}{c}\text { Percentage } \\
(\mathbf{1 0 0 \% )}\end{array}$ \\
\hline- & 41 & 40.2 \\
- & High & 61 & 59.8 \\
\hline
\end{tabular}

Source: Field data (2017)

The categorization indicates that majority, $59.8 \%$ (61/102) of the nurses were less knowledgeable on the epilepsy.

\section{Nurses' attitude towards People with Epilepsy}

Since the nurses' attitude could influence their practice towards the disease, it was important to assess the nurses' position towards epilepsy. In terms of PWE having the same intelligence as nonepileptics, out of the 102 respondents, 34.3\% supported that idea. About 8.8\% respondents were of the view that PWE could have the same employment as the general public do. When it came to relationship, $6.9 \%$ of the nurses said they would have amorous relationship with PWE for which they were also right in their responses, and $17.6 \%$ of the nurses do not suspect PWE to have mental illness.

\section{Ways of transmission of epilepsy}

Results on this item showed clearly that out of the 102 study participants, majority responded in the negative to the items given on the questionnaire, which they were all correct. In terms of Urine, 99.0\% answered "No," likewise response for Flatus (97.1\%) and Faeces (95.1\%). In connection with Marriage, majority (91.2\%) opted "No," and the same negative response for Physical contact $(89.2 \%)$ and Sharing of food $(85.3 \%)$ respectively. Furthermore, results on this item indicated that $95.1 \%(97 / 102)$ of the nurses responded "No," meaning that breathe of epileptic patient is not infectious. Also, 97.1\% (99/102) of the nurses responded "No" the droppings of animals cannot spread epilepsy. Notwithstanding, none of the respondents could mention any animal(s) whose droppings can spread epilepsy. Furthermore, 97.1\% (99/102) of the respondents disclaimed that coming in contact with the excretions (body fluids) from PWE can be infectious. It was observed from the data that all the nurses $(100 \%)$ agreed to the fact that saliva could not be a way of transmission of epilepsy. It was observed from the result that respondents disclaimed, denied and refuted the fact that epilepsy is neither an air-borne disease, nor an animal dropping transmitted disease, and is not contagious through the excretion of body fluids. The detail result of the attitude towards epilepsy is in Table 4. 
American Journal of Health, Medicine and Nursing Practice

ISSN 2520-4017 (Online)

Vol.5, Issue 1 No.4, pp 43 - 65, 2020

www.ajpojournals.org

Table 4: Attitude towards epilepsy

\begin{tabular}{|c|c|c|}
\hline \multirow[t]{2}{*}{ Attitude } & \multicolumn{2}{|c|}{ Response rate $(\mathrm{N}=102)$} \\
\hline & Correct $(\%)$ & Wrong (\%) \\
\hline \multicolumn{3}{|l|}{ Nurses attitude towards PWE } \\
\hline - Have same intelligence & $35(34.3 \%)$ & $67(65.7 \%)$ \\
\hline - Have same employment & $9(8.8 \%)$ & $93(91.2 \%)$ \\
\hline - Amorous relationship & $7(6.9 \%)$ & $95(93.1 \%)$ \\
\hline - $\quad$ Suspicion of mental illness & $18(17.6 \%)$ & $84(82.4 \%)$ \\
\hline \multicolumn{3}{|l|}{ Ways of transmission } \\
\hline - Urine & $101(99.0 \%)$ & $1(1.0 \%)$ \\
\hline - Flatus & $99(97.1 \%)$ & $3(2.9 \%)$ \\
\hline - Animal dropping & $99(97.1 \%)$ & $3(2.9 \%)$ \\
\hline - Excretions/body fluids & $99(97.1 \%)$ & $3(2.9 \%)$ \\
\hline - Breath from epileptics & $97(95.1 \%)$ & $5(4.9 \%)$ \\
\hline - Faeces & $97(95.1 \%)$ & $5(4.9 \%)$ \\
\hline - Marriage & $93(91.2 \%)$ & $9(8.8 \%)$ \\
\hline - Physical contact & $91(89.2 \%)$ & $11(10.8 \%)$ \\
\hline - Sharing of food & $87(85.3 \%)$ & $15(14.7 \%)$ \\
\hline - Saliva & $102(100.0 \%)$ & $0(0.0 \%)$ \\
\hline
\end{tabular}

Source: Field data (2017)

\section{Categorization of attitude towards epilepsy}

Attitude towards epilepsy was operationally classified into positive and negative attitudes. Respondents who had three appropriate responses on the attitude were seen as having "positive" attitude towards epilepsy, and those who had four or more inappropriate responses were thus classified as having "negative" attitude towards epilepsy. The table 5 below highlights on the attitude categorization.

Table 5: Categorization of attitude towards epilepsy

\begin{tabular}{ccc}
\hline Attitude & Frequency $(\mathbf{N = 1 0 2})$ & Percentage (100\%) \\
\hline$-\quad$ Positive & 72 & 70.6 \\
$-\quad$ Negative & 30 & 29.4 \\
\hline
\end{tabular}

Source: Field data (2017)

Looking at the categorization above, it is clear that $70.6 \%(70 / 102)$ of the nurses have positive attitude towards PWE.

However, when the nurses' behaviour was tested with knowledge on epilepsy, no statistical significance was observed $(\mathrm{p}=0.120)$. More so, when the attitude was cross-tabulated with knowledge on epilepsy, there was no statistical association between them $(p=0.192)$. When the attitude was observed in connection with practices on epilepsy, a significant difference was observed for positive attitude $(\mathrm{p}=0.008)$. Table 6 below throws light on it. 
Table 6: Attitude and practices on epilepsy

\begin{tabular}{|c|c|c|c|}
\hline \multirow[t]{2}{*}{ Attitude } & \multicolumn{2}{|c|}{ Practices on epilepsy } & \multirow[t]{2}{*}{ p-value } \\
\hline & $\begin{array}{c}\text { Good }(N=48) \\
(100 \%)\end{array}$ & $\begin{array}{c}\text { Poor }(\mathrm{N}=54) \\
(100 \%)\end{array}$ & \\
\hline - $\quad$ Positive & $40(83.3 \%)$ & $32(59.3 \%)$ & $0.008 *$ \\
\hline - Negative & $8(16.7 \%)$ & $22(40.7 \%)$ & \\
\hline
\end{tabular}

\section{Practices on Epilepsy}

This covers items such as what to do when seizures occurs, counselling nurses offer to PWE, and the preferred choice for the treatment of epilepsy. When the skills of the nurses were assessed on managing epilepsy during the attack, out of the 102 respondents for the study, majority (87.3\%) said they "No" they would not keep/run away in the face of epileptic crisis, $81.4 \%$ also indicated same response that they would not touch the patient, and most said "Yes" to performing first aid measures (68.6\%). All the above responses were correct. In terms of counselling the patient, the responses of the study participants were all in the affirmative for which they were right. Avoid heights was positively indicated by $24.5 \%$ of the participants, Avoid alcohol (32.4\%), Take drugs as prescribed (26.5\%), Regular exercise (10.8\%), and Get plenty of sleep (14.7\%).

In the case of preferred choice for treatment, with the exception of Orthodox medicine which the respondents answered "Yes" for 66.7\% (68/102) of the nurses and they were right, the rests of the responses were all in the negative for which the study participants were also correct for their answers. For those who said they would not encourage Prayer camp healing were $80.4 \%$, Traditional/herbal treatment (50.8\%), Fetish healing (85.3\%) and Animal sacrifice (93.1\%). Despite the fact that epilepsy is treatable, their choice of treatment for epilepsy was against the religiospiritual domain. Table 4 highlights the details of the practices on epilepsy.

The fact that some of the nurses complained of lack of supply of anticonvulsants or antiepileptic agents (AEDs) from the district medical store, some of the agents mentioned in the management of epilepsy in their facilities or clinics include Phenobarbitone 34.3\% (35/102), Diazepam 19.6\% (20/102), Carbamazepine 14.7\% (15/102) and Phenytoin 24.5\% (25/102) among other drugs. It is therefore worth mentioning that at least the respondents were aware of some of the anticonvulsants/antiepileptics. Therefore, managing cases of seizure attacks in their communities should not be a problem. 
American Journal of Health, Medicine and Nursing Practice

ISSN 2520-4017 (Online)

Vol.5, Issue 1 No.4, pp 43 - 65, 2020

www.ajpojournals.org

Table 7: Practices on Epilepsy

\begin{tabular}{|c|c|c|}
\hline \multirow[t]{2}{*}{ Practices } & \multicolumn{2}{|c|}{ Response rate $(\mathrm{N}=102)$} \\
\hline & Correct (\%) & Wrong (\%) \\
\hline \multicolumn{3}{|l|}{ What to do when seizure occurs } \\
\hline - Keep/Run away & $89(87.3 \%)$ & $13(12.7 \%)$ \\
\hline - Touching patient & $83(81.4 \%)$ & $19(18.6 \%)$ \\
\hline - $\quad$ Perform first aid measures & $70(68.6 \%)$ & $32(31.4 \%)$ \\
\hline \multicolumn{3}{|l|}{ Counselling to patient } \\
\hline - Avoid heights & $26(24.5 \%)$ & $76(74.5 \%)$ \\
\hline - Avoid alcohol & $33(32.4 \%)$ & $69(67.7 \%)$ \\
\hline - $\quad$ Take drugs as prescribed & $27(26.5 \%)$ & $75(73.5 \%)$ \\
\hline - Regular exercise & $11(10.8 \%)$ & $91(89.2 \%)$ \\
\hline - Get plenty of sleep & $15(14.7 \%)$ & $87(85.3 \%)$ \\
\hline \multicolumn{3}{|l|}{ Preferred choice for treatment } \\
\hline - $\quad$ Prayer camp healing & $82(80.4 \%)$ & $20(19.6 \%)$ \\
\hline - Traditional/herbal & $61(50.8 \%)$ & $41(40.2 \%)$ \\
\hline - $\quad$ Fetish healing & $87(85.3 \%)$ & $15(14.7 \%)$ \\
\hline - Animal sacrifice & $95(93.1 \%)$ & $7(6.9 \%)$ \\
\hline - Orthodox medicine & $68(66.7 \%)$ & $34(33.3 \%)$ \\
\hline \multicolumn{3}{|l|}{ Drugs used in the treatment } \\
\hline - Phenobarbitone & $35(34.3 \%)$ & - \\
\hline - Diazepam & $20(19.6 \%)$ & - \\
\hline - Carbamazepine & $15(14.7 \%)$ & - \\
\hline - Phenytoin & $25(24.5 \%)$ & - \\
\hline - Other drugs & $7(6.9 \%)$ & - \\
\hline
\end{tabular}

Source: Field data (2017)

\section{Categorization of practices on epilepsy}

On the practices on epilepsy, participants who had nine or more appropriate (correct) responses out of the 18 items were operationally labelled as having "good" practices, and those who scored from one to eight were operationally categorised as having "poor" practices. This is shown in table 8 below.

Table 8: Level of practices on epilepsy

\begin{tabular}{ccc}
\hline Practice & Frequency $\mathbf{( N = 1 0 2})$ & Percentage (100\%) \\
$-\quad$ Good & 48 & 47.1 \\
$-\quad$ Poor & 54 & 52.9 \\
\hline
\end{tabular}

Source: Field data (2017)

Analysis from the table above indicates that more than half 52.9\% (54/102) of the nurses had poor practices on epilepsy. 
American Journal of Health, Medicine and Nursing Practice

ISSN 2520-4017 (Online)

Vol.5, Issue 1 No.4, pp 43 - 65, 2020

www.ajpojournals.org

\section{Bivariate Analyses}

These analyses were carried out to see the strength of the independent variables as against the dependent variables to ascertain their statistical significance to the study. When the sociodemographic characteristics was cross-tabulated with knowledge of epilepsy, a significant difference was observed among religion $(\mathrm{p}=0.017)$, specialty area $(\mathrm{p}=0.045)$, and close family relationship with epilepsy $(\mathrm{p}=0.001)$. This is shown in Table 9. More so, when the sociodemographic characteristics was cross-tabulated with practice on epilepsy, area of specialty $(\mathrm{RMN})(\mathrm{p}=0.001)$ appeared statistically significant. This is also indicated in table 10.

Table 9: Socio-demographic factors and knowledge on epilepsy

\begin{tabular}{|c|c|c|c|c|}
\hline \multirow{2}{*}{\multicolumn{2}{|c|}{ Variable }} & \multicolumn{2}{|c|}{ Knowledge on epilepsy } & \multirow[t]{2}{*}{ p-value } \\
\hline & & $\begin{array}{c}\text { High }(\mathrm{N}=41) \\
(100 \%)\end{array}$ & $\begin{array}{c}\text { Low }(\mathrm{N}=61) \\
(100 \%)\end{array}$ & \\
\hline \multicolumn{5}{|c|}{ Age } \\
\hline & $21-30$ years & $30(73.3 \%)$ & $50(82.0 \%)$ & \multirow{4}{*}{0.234} \\
\hline & $31-40$ years & $7(17.1 \%)$ & $10(16.4 \%)$ & \\
\hline & $41-50$ years & $2(4.8 \%)$ & $1(1.6 \%)$ & \\
\hline & $51-60$ years & $2(4.8 \%)$ & $0(0.0 \%)$ & \\
\hline \multicolumn{5}{|c|}{ Sex } \\
\hline & Male & $6(14.6 \%)$ & $7(11.5 \%)$ & \multirow[t]{2}{*}{0.133} \\
\hline & Female & $35(85.4 \%)$ & $54(88.5 \%)$ & \\
\hline \multicolumn{5}{|c|}{ Religion } \\
\hline & Christianity & $30(73.2 \%)$ & $53(86.9 \%)$ & \multirow{4}{*}{$0.017 *$} \\
\hline & Muslim & $7(17.1 \%)$ & $5(8.2 \%)$ & \\
\hline & Traditionalist & $4(9.7 \%)$ & $0(0.0 \%)$ & \\
\hline & Others & $0(0.0 \%)$ & $3(4.9 \%)$ & \\
\hline \multicolumn{5}{|c|}{ Speciality area } \\
\hline & RGN & $4(9.8 \%)$ & $5(8.2 \%)$ & \multirow{5}{*}{$0.045^{*}$} \\
\hline . & $\mathrm{RMN}$ & $2(4.9 \%)$ & $0(0.0 \%)$ & \\
\hline & $\mathrm{RM}$ & $3(7.3 \%)$ & $0(0.0 \%)$ & \\
\hline . & $\mathrm{CHN}$ & $16(39.0 \%)$ & $36(59.0 \%)$ & \\
\hline 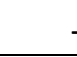 & Others & $16(39.0 \%)$ & $20(32.8 \%)$ & \\
\hline \multicolumn{5}{|c|}{$\begin{array}{l}\text { Close family } \\
\text { relationship with } \\
\text { epilepsy }\end{array}$} \\
\hline & Yes & $8(12.2 \%)$ & $1(8.2 \%)$ & \multirow[t]{2}{*}{$0.001 *$} \\
\hline . & No & $34(87.8 \%)$ & $56(91.8 \%)$ & \\
\hline
\end{tabular}

$(*)=\mathrm{p}$ is statistically significant based on chi square analysis $\quad$ Source: Field data (2017) 
American Journal of Health, Medicine and Nursing Practice

ISSN 2520-4017 (Online)

Vol.5, Issue 1 No.4, pp 43 - 65, 2020

www.ajpojournals.org

Table 10: Socio-demographic factors and practices

\begin{tabular}{|c|c|c|c|c|}
\hline \multirow{2}{*}{\multicolumn{2}{|c|}{ Variable }} & \multicolumn{2}{|c|}{ Practices on epilepsy } & \multirow[t]{2}{*}{ p-value } \\
\hline & & $\begin{array}{c}\text { Good }(N=48) \\
(100 \%) \\
\end{array}$ & $\begin{array}{c}\text { Poor }(N=54) \\
(100 \%)\end{array}$ & \\
\hline \multicolumn{5}{|l|}{ Age } \\
\hline- & $21-30$ years & $34(70.8 \%)$ & $47(87.0 \%)$ & 0.192 \\
\hline & $31-40$ years & $8(16.6 \%)$ & $6(11.1 \%)$ & \\
\hline & $41-50$ years & $3(6.3 \%)$ & $1(1.9 \%)$ & \\
\hline - & $51-60$ years & $3(6.3 \%)$ & $0(0.0 \%)$ & \\
\hline \multicolumn{5}{|l|}{ Sex } \\
\hline & Male & $13(14.6 \%)$ & $6(13.04 \%)$ & 0.189 \\
\hline- & Female & $43(85.4 \%)$ & $40(87.0 \%)$ & \\
\hline \multicolumn{5}{|c|}{ Religion } \\
\hline & Christianity & $44(73.2 \%)$ & $38(82.6 \%)$ & 0.065 \\
\hline 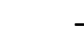 & Muslim & $8(17.1 \%)$ & $5(10.9 \%)$ & \\
\hline & Traditionalist & $4(9.7 \%)$ & $0(0.0 \%)$ & \\
\hline- & Others & $0(0.0 \%)$ & $3(6.5 \%)$ & \\
\hline \multicolumn{5}{|c|}{ Speciality area } \\
\hline- & RGN & $9(16.2 \%)$ & $5(10.9 \%)$ & \\
\hline . & RMN & $6(10.7 \%)$ & $0(0.0 \%)$ & $0.001 *$ \\
\hline- & $\mathrm{RM}$ & $5(8.9 \%)$ & $0(0.0 \%)$ & \\
\hline- & $\mathrm{CHN}$ & $18(32.1 \%)$ & $31(67.4 \%)$ & \\
\hline 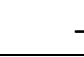 & Others & $18(32.1 \%)$ & $10(21.7 \%)$ & \\
\hline
\end{tabular}

Close family

relationship with

epilepsy

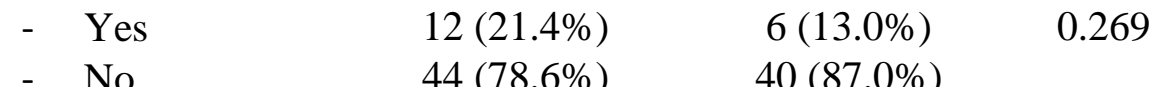

$(*)=\mathrm{p}$ is statistically significant based on chi square analysis $\quad$ Source: Field data (2017)

\section{Knowledge on epilepsy and practices}

This section looks at the strengths of association between practices on epilepsy among other independent variables. Their statistical significance is determined by their $p$-values $(p<0.050)$. When the strength of knowledge on epilepsy was associated with practices on epilepsy based on the categorisation, no significant difference was observed. This is indicated in table 11 below. As shown in table 12, none of the independent variables under practices on epilepsy showed a statistical significance with knowledge on epilepsy. 
American Journal of Health, Medicine and Nursing Practice

ISSN 2520-4017 (Online)

Vol.5, Issue 1 No.4, pp 43 - 65, 2020

www.ajpojournals.org

Table 11: Knowledge and practices on epilepsy

\begin{tabular}{lccc}
\hline Knowledge on & \multicolumn{2}{c}{ Practice } & p-value \\
\cline { 2 - 3 } epilepsy & $\begin{array}{c}\text { Good }(\mathbf{N = 4 8}) \\
(\mathbf{1 0 0 \%})\end{array}$ & $\begin{array}{c}\text { Poor }(\mathbf{N = 5 4 )} \\
(\mathbf{1 0 0 \%})\end{array}$ & \\
\hline$-\quad$ High & $23(47.9 \%)$ & $18(33.3 \%)$ & 0.134 \\
$-\quad$ Low & $25(52.1 \%)$ & $36(66.7 \%)$ & \\
\hline Source: Field data $(2017)$ & &
\end{tabular}

Table 12: Practices and knowledge on epilepsy

\begin{tabular}{|c|c|c|c|}
\hline \multirow[t]{2}{*}{ Variable } & \multicolumn{2}{|c|}{ Knowledge on epilepsy } & \multirow[t]{2}{*}{ p-value } \\
\hline & $\begin{array}{c}\text { High }(\mathrm{N}=41) \\
(100 \%)\end{array}$ & $\begin{array}{c}\text { Low }(N=61) \\
(100 \%)\end{array}$ & \\
\hline \multicolumn{4}{|c|}{ What do you do when seizure occurs? } \\
\hline \multicolumn{4}{|c|}{ Keep/Run away } \\
\hline - Yes & $4(9.8 \%)$ & $9(14.8 \%)$ & 0.583 \\
\hline$-\quad \mathrm{No}$ & $37(90.2 \%)$ & $52(85.2 \%)$ & \\
\hline \multicolumn{4}{|c|}{$\begin{array}{l}\text { Not touching the } \\
\text { person }\end{array}$} \\
\hline - Yes & $10(24.4 \%)$ & $6(9.8 \%)$ & 0.087 \\
\hline - No & $31(75.6 \%)$ & $55(90.2 \%)$ & \\
\hline \multicolumn{4}{|c|}{$\begin{array}{l}\text { Perform first-aid } \\
\text { measures }\end{array}$} \\
\hline - Yes & $27(65.9 \%)$ & $47(77.0 \%)$ & 0.310 \\
\hline - $\quad$ No & $14(34.1 \%)$ & $14(23.0 \%)$ & \\
\hline \multicolumn{4}{|c|}{ Counselling a person with epilepsy } \\
\hline \multicolumn{4}{|c|}{ Avoid heights } \\
\hline - Yes & $8(19.5 \%)$ & $23(37.7 \%)$ & 0.057 \\
\hline - No & $33(80.5 \%)$ & $38(62.3 \%)$ & \\
\hline \multicolumn{4}{|l|}{ Avoid alcohol } \\
\hline - Yes & $28(68.3 \%)$ & $38(62.3 \%)$ & 0.426 \\
\hline - No & $13(31.7 \%)$ & $23(37.7 \%)$ & \\
\hline \multicolumn{4}{|l|}{$\begin{array}{l}\text { Take drug as } \\
\text { prescribed }\end{array}$} \\
\hline - Yes & $11(26.8 \%)$ & $14(23.0 \%)$ & 0.837 \\
\hline$-\quad$ No & $30(73.2 \%)$ & $47(77.0 \%)$ & \\
\hline \multicolumn{4}{|c|}{ Regular exercise } \\
\hline - Yes & $7(17.1 \%)$ & $6(9.8 \%)$ & 0.288 \\
\hline - $\quad$ No & $34(82.9 \%)$ & $55(90.2 \%)$ & \\
\hline \multicolumn{4}{|c|}{ Get plenty of sleep } \\
\hline - Yes & $5(12.2 \%)$ & $9(14.8 \%)$ & 0.801 \\
\hline - No & $36(87.8 \%)$ & $52(85.2 \%)$ & \\
\hline
\end{tabular}

Source: Field data (2017)

When knowledge on epilepsy was associated with preferred treatment for epilepsy, no significant association was observed. Table 13 gives the highlights of the association. 
American Journal of Health, Medicine and Nursing Practice

ISSN 2520-4017 (Online)

Vol.5, Issue 1 No.4, pp 43 - 65, 2020

www.ajpojournals.org

Table 13: Knowledge on epilepsy and Preferred treatment Variable

Knowledge on epilepsy

p-value

\section{High $(\mathbf{N}=41) \quad$ Low $(\mathrm{N}=61)$}

$(100 \%)$ $(\mathbf{1 0 0 \%})$

\begin{tabular}{llll}
\hline $\begin{array}{l}\text { Preferred choice of } \\
\text { treatment }\end{array}$ & & & \\
\hline Payer camp healing & $6(14.6 \%)$ & $12(19.7 \%)$ & 0.504 \\
- Yes & $35(85.4 \%)$ & $49(80.3 \%)$ & \\
- No & &
\end{tabular}

Traditional/Herbal

medicine

- Yes

$15(36.6 \%)$

$27(44.3 \%)$

0.470

- No $26(63.4 \%)$ $34(55.7 \%)$

Orthodox medicine

- Yes

$8(19.5 \%)$

$5(8.2 \%)$

0.407

- No

$33(80.5 \%)$

$56(91.8 \%)$

Fetish healing

- Yes

$3(7.3 \%)$

$4(6.6 \%)$

0.602

- No

$48(92.7 \%)$ $57(93.4 \%)$

Animal sacrifice

- Yes

$$
0(0.0 \%)
$$

$3(4.9 \%)$

$41(100.0 \%)$

$58(95.1 \%)$

Source: Field data (2017)

\section{DISCUSSION}

This study assessed the knowledge, attitude and practice regarding epilepsy among nurses in Asutifi North District in the Brong Ahafo Region of Ghana.

The knowledge of the study participants on epilepsy regarding the causes in the development of epilepsy was analyzed. The results on knowing the cause of epilepsy indicated that a majority 69 $(67.7 \%)$ of the nurses responded 'Yes' knowing the causes of epilepsy whilst $33(32.4 \%)$ said 'No'. This implies that majority of the nurses have basic knowledge about the causes of epilepsy. This assertion was in sharp contrast to a study in Ghana that indicated $172(45.3 \%)$ of the respondents did not know the cause of epilepsy among literate adults in urban population, saying they are ignorant of the cause of the disease [14].

On the perceived causes of epilepsy, $49(48.0 \%)$ of the nurses associated birth trauma to be the cause of epilepsy, $25(24.5 \%)$ knew of brain injury, 23 (22.6\%) claimed hereditary as a cause of epilepsy whilst $10(9.8 \%)$ of the nurses said brain infection is also a cause of epilepsy. However, $14(13.7 \%)$ of the respondents attributed witchcraft to be the cause of epilepsy, spiritual possession accounting for $12(11.8 \%)$ of the respondents, few 7 (6.7\%) of the respondents said it is caused by curses and $6(5.9 \%)$ also said epilepsy could be caused by poisoning or bad blood. This result is in harmony with other studies conducted in Ghana [14,16] and Uyo, Southern Nigeria [17]. It can be deduced that the causes of epilepsy within the Asutifi North District are categorized into 
physiological and cultural superstitious causes of the disorder. Specifically, the physiological causes took the form of brain injury, birth trauma and brain infection whilst the cultural superstitious causes also manifested through curse, heredity, spiritual possession and poisoning or bad blood. When knowledge on epilepsy was associated with socio-demographic characteristics, a significant difference was observed among Muslim religion $(\mathrm{p}=0.017)$, specialty area $(\mathrm{RMN})$ $(\mathrm{p}=0.045)$ and close family relationship with epilepsy $(\mathrm{p}=0.001)$.

When factors that could trigger seizure in people with epilepsy were assessed, $46(45.1 \%)$ of nurses identified lack of sleep as a contributory factor that could trigger seizure in epileptic patients, 37 (36.3\%) cited stress whilst $4(3.9 \%)$ attributed fast breathing to trigger seizure in epileptic patients with few $9(8.8 \%)$ affirming staring at computer screen for too long. This result is indicating that majority of the nurses did not know what could trigger seizure in people living with epilepsy as most of their responses were in the negative. However, seizures could be triggered in anyone under certain conditions such as life-threatening dehydration or high temperature among other factors [39].

Regarding manifestation of epilepsy, $62(60.8 \%)$ nurses said jerking of the body is a manifestation of epilepsy, followed by loss of consciousness $50(49.0 \%)$; $46(45.1 \%)$ of nurses knew foaming of the mouth as a manifestation of epilepsy; 49 (48.0\%) knew falling down to be a manifestation of epilepsy, while shouting was described by 32 (31.4\%) nurses as manifestation of epilepsy. 31 (30.4\%) of respondents identified rolling of the eye and tongue biting as manifestation of epilepsy, $24(23.5 \%)$ respondents said urination is manifestation of epilepsy with only a few $16(15.7 \%)$ respondents associating abnormal behaviour to epilepsy. The few who responded in the affirmative result was in consonance with other studies that cited responses such as convulsion, falling down, rolling of eyes, foaming of mouth, urination, and biting of tongue as manifestations of epileptic attack $[7,19]$. This indicates that majority of the nurses did not the manifestations of epilepsy.

Though majority of the nurses did not consent to this notion of transmission of the disease, the few $15(14.7 \%)$ respondents perceived sharing of food could possibly transmit epilepsy, and 11 $(10.8 \%)$ nurses said physical contact with a patient can facilitate transmission of the disease whilst $9(8.8 \%)$ respondents said it could be transmitted through marital union. On other ways of transmission of the disease, $5(4.9 \%)$ indicated breath from an epileptic patient is infectious, $3(2.9 \%)$ said animal dropping and contact with excretions respectively from epileptic patients could spread the disease. This result confirms other studies where respondents were of the view that epilepsy is contagious and could be spread through contact (physical), saliva, blood, urine, and faeces/flatus $[14,21,17,22,23]$.

In terms of amorous relationship, $95(93.1 \%)$ of the respondents posited that they will not engage themselves in amorous relationship with a person with epilepsy. It was reported that 44.8 percent of respondents refused to marry people with epilepsy [41]. This is in consistent with the findings of this research report. In support of the findings of this research, it has been reported that approximately 25 percent of health care workers would not allow their child to marry someone with epilepsy and 20 percent thought people with epilepsy should not marry [43].

In sharp contrast to the findings of this study, epilepsy does not appear to be a major stress factor in marriage as long as the spouse is knowledgeable about the condition. Such couples often exhibit 
a greater degree of mutual concern and support [46]. In support of the counter argument, it has also been indicated that 85.1 percent of their respondents approved marrying an epileptic [29].

When attitude towards epilepsy was associated with the socio-demographic characteristics to determine its influence, a significant difference was observed among sex (female) $(\mathrm{p}=0.037)$, religion (Muslim) $(\mathrm{p}=0.012)$, and specialty area $(\mathrm{RMN})(\mathrm{p}=0.054)$, and there was no statistical significance on how age and close family relationship with epilepsy influence knowledge on the disease.

However, $84(82.4 \%)$ of the nurses suspect epileptic people to have mental illness. In tune with the result from this analysis, a cited report has argued that 10 percent of respondents equated epilepsy with insanity [42]. More so, report from other studies have shown that people with less awareness and knowledge about epilepsy tend to have negative attitudes toward the disease and misperceptions such as epilepsy being a form of insanity [28]. It is obvious from the discussions on this issue of suspicion of mental illness that majority of the nurses for this study associate epilepsy with mental illness and this points to lack of knowledge of the disease. In sharp contrast to the findings of this research is the revelation that the highly educated did not view epileptics as not mentally sick persons [14].

Data from this study further stressed that 67 (65.7\%) of the respondents agreed that people with epilepsy do not have the same intellectual capabilities as the general public. In affirming the findings of this research, people with mild to moderate intellectual disability (ID) lifetime epilepsy have been reported to have prevalence at between six and 15 percent. In those with severe ID epilepsy occurs in around 25 percent whilst in those with profound ID (IQ<20) [44]. These findings show a strong correlation between epilepsy and intellectual capabilities of PWE. However, there is a disagreement with the findings of this research as it is purported that most people with epilepsy do not have intellectual disabilities [45]. By endorsement of this view, it is published in a study that $60(88.23 \%)$ of their respondents support the idea that persons with epilepsy can have university education [28].

In connection with employment, nine $(8.8 \%)$ of respondents were of the view that persons with epilepsy be employed in the same job as other people, with majority 93 (91.2\%) saying "No". Deductions from this data showed that the nurses have poor attitude towards PWE as this is evident by their utmost responses given that epileptic people have psychological deficiencies, mental disorders and behaviour leading to a deficiency in their intellectual abilities, and for that matter cannot be employed in the same job as other people. A statement confirmed this assertion in this research by saying that persons with epilepsy are shunned and discriminated against in employment in Africa because epilepsy is seen as a highly contagious and shameful disease in the eyes of the public [7]. A similar finding in a study has estimated 25 percent of their respondents reported that people with epilepsy cannot work like others [22]. Notwithstanding, a publication contradicts this study where it is observed in that study that the majority of the respondents would offer a job (90.4\%) [29]. In defense of this notion is a publication in a study that $57(86.36 \%)$ of their respondents believe that persons with epilepsy can get opportunities of appropriate occupation [28]. 
Due to the training nurses have gone through, $70(68.6 \%)$ of the nurses responded that they will perform recommended first-aid measures on epileptic person when seizure occurs, 19 (18.6\%) of the nurses responded that they will not touch the patient whilst $13(12.8 \%)$ of the nurses responded that they will keep/run away for fear of the attack. For the nurses who claimed they will perform recommended first-aid measures, $54(77.1 \%)$ of them said they will reassure the patient that he or she will be well and refer him or her for appropriate medical treatment, whilst $16(22.9 \%)$ after the recommended first-aid is given they will clean the person up and ask him to continue his or her journey. This result is not far from a description that portrays that the most important nursing intervention is to keep up an adequate airway, breathing and circulation during sei $\neg$ zures and to prevent any injury of the patients with epilepsy. Besides, an oral airway suction apparatus should be available at bedside at all times [34] to reduce danger whiles optimizing results in the management of the patient [35].

\section{CONCLUSION}

Nurses at the Asutifi North District tended to have low knowledge, positive attitude and poor practices on epilepsy. This is because there still exist cultural beliefs among some of the respondents on the spread of the disease as heredity, spiritual possession and curse. These serve as a drawback to the positive attitudes shown towards epilepsy. It is therefore important to improve training and health care delivery for epilepsy.

\section{RECOMMENDATION}

The Ghana Health Service in collaboration with the Ministry of Health should run intermediary workshops, at least every six months, to train nurses in epilepsy diagnoses to reduce the treatment gap. The health directorate of the district should raise awareness and educate the communities on epilepsy. Enhancing nursing education and training on epilepsy by the Ministry of Health and its agencies is imperative to improving health care delivery for people living with the disease. Health education and promotion programs should be geared towards destigmatizing epilepsy among health professionals and the general public.

\section{REFERENCES}

1. Dung, A. A. D., Singh, H. K., Kumari, S., Gupta, M., Raval, M., \& Rajender, G. (October, 2009). Knowledge, Attitude and Perception of Caregivers of Children with Epilepsy. Delhi Psychiatry Journal, 12(2), 274-275. Retrieved January 30, 2017 from http://www.medind.nic.in/daa/t09/i2/daat092ip274.pdf.

2. Shahbo, G. M. A. E. M., Bharathi, B., \& Daoala, A. L. (2014). A comparative study on knowledge, attitude and believes of epilepsy among communities of Egypt and Kingdom of Saudi Arabia. IOSR Journal of Nursing and Health Science, 3(5) Ver. I, 97-107. Available at Www.iosrjournals.org.

3. Verma, G., \& Vankar, G. K. (November, 2016). Does a didactic lecture on epilepsy for nursing students improve knowledge and attitude? International Journal of Science and Research (IJSR), 5(11): 992-994. Retrieved January 27, 2018 from https://www.ijsr.net/archive/v5i11/ART20162919.pdf. 
4. Al-Adawi, S. H. N., Al-Maskari, M. Y., Martin, R, G., Al-Naamani, A. N. H., Al-Riyamy, K. A., \& Al-Hussaini, A. A. A. (2000). Attitudes of Omani physicians to people with epilepsy. Neurosciences, 5(1): 18-21.

5. Epilepsy Foundation. (2017). International Epilepsy Day 2017 - February $13^{\text {th }}$, Putting Epilepsy in the Picture. Retrieved February 14, 2017 from http://www.epilepsy.com/makedifference/get-involved/international-epilepsy-day.

6. Dalrymple, J., \& Appleby, J. (2000). Cross Sectional Study of Reporting of Epileptic Seizures to General Practitioners. British Medical Journal, 320: pp 94-97.

7. Kabir, M., Iliyasu, Z., Abubakar, I. S., Kabir, Z. S., \& Farinyaro A. U. (2005). Knowledge, attitude and beliefs about epilepsy among adults in a Northern Nigerian urban community. Annals of African Medicine, 4(3): pp 107-112.Accessed January 18, 2018 from http://www.bioline.org.br/request?am05028.

8. Wikipedia (June, 2018). Convulsion. Retrieved July 13, 2018 from https://en.m.wikipedia.org/wiki/Convulsion.

9. World Health Organization. (2004). Epilepsy in the WHO African Region: Bridging the Gap: The Global Campaign Against Epilepsy "Out of the Shadows”. Brazzaville, Congo: WHO.

10. Atlas of Epilepsy Care in the World (2005). Geneva: WHO Press.

11. Ghana Health Service. (2015). Dr. Patrick Adjei speaks on epilepsy stigmatization. Accessed December 3, 2016 from http://www.ghanahealthservice.org/ghs-itemdetails.php?acid=22\&iid=111.

12. de Boer, H. M., Mula, M., \& Sander,J. W. (2008). Review: The global burden and stigma of epilepsy. Epilepsy \& Behavior, 12:540-546.

13. Linehan, C., Walsh, P. N., Kerr, M., Brady, G., \& Kelleher, C. (2009). The prevalence of epilepsy in Ireland. Dublin: Brainwave The Irish Epilepsy Association.

14. Nyame P. K., \& Biritwum, R.B. (1997). Epilepsy: Knowledge, attitude and practice in literate urban population, Accra, Ghana. West Africa Journal of Medicine, 16(3): pp 139-145.

15. Ghana Health Service. (2016). DHIMS. Retrieved December 5, 2016 from https://dhims.chimgh.org/dhims/dhis-web-pivot/.

16. Adjei, P., Akpalu, A., Laryea, R., Nkromah, K., Sottie, C., Ohene, S., \& Osei, A. (2013). Beliefs on epilepsy in Northern Ghana. Epilepsy and Behavior, 29(2): pages 316-321. doi: http://dx.doi.org/10.1016/j.yebeh.2013.07.034.

17. Ekeh, B. C., \& Ekrikpo, U. E. (2015). The knowledge, Attitude, and Perception towards Epilepsy amongst Medical Students in Uyo, Southern Nigeria. Advances in Medicine, Volume 2015, Article ID 876135, 6 pages. doi: http://dx.doi.org/101155/2015/876135. 
18. Sahni, P. (2002). Epilepsy in Africa and the African American Community. Ontario: Diversity resources, Inc.

19. Millogo, A., Ratsimbazafy, V., Nubukpo, P., Barro, S., Zongo, I., \& Preux, P. M. (April, 2004). Epilepsy and traditional medicine in Bobo-Dioulasso (Burkina Faso). Acta Neurologica Scandinavica, Volume 109, Issue 4; Pages 250-254. doi:10.1111/j.16000404.2004.00248.x.

20. Fernandes, P.T., Cabral, P., Araujo, U., Noronha, A.L.A., \& Li, M. L. (2005). Kids' perception about epilepsy. Epilepsy and Behaviour, 6: pp 601-603.

21. Kassie, G. M., Kebede, T. M., \& Duguma, B. K. (August, 2014). Knowledge, attitude, and practice of epileptic patients towards their illness and treatment in Jimma University Specialized Hospital, Southwest Ethiopia. North American Journal of Medical Sciences, 6(8): pages 383-390. doi:10.4103/1947-2714.139288.

22. Sureka, R. K., Agarwal, A., Chaturvedi, S., Yadav, K. S., \& Kumar, S. (October 26, 2015). Knowledge, attitude and practice of epilepsy among nursing faculty and students in a tertiary care center in Rajasthan. Journal of Evidence based Medicine and Healthcare, 2(43): pages 7673-7679. doi:10.18410/jebmh/2015/1037.

23. Ankaful Psychiatric Hospital (2003). The top ten common diseases at the Ankaful Psychiatric Hospital. Ankaful News Flash, 5(2), p 5.

24. Ajibade, B. L., Fabiyi, B., Ajao, O. O., Olabisi, O. I., \& Akinpelu, A. O. (March, 2016). Public attitude and social support towards people living with epilepsy (PWE) amongst communities, in a selected local government of Oyo State, Nigeria. International Journal of Nursing, Midwife and Health Related Cases, 2(1): pages 18-48. Retrieved January 20, 2018 from http://www.eajournals.org/wp-content/uploads/Public-Attitude-and-Social-Supporttowards-People-Living-With-Epilepsy-PWE-Amongst-Communities.pdf.

25. World Health Organization. World Health Report (2007). Mental health: New understanding, new hope. Geneva: WHO.

26. Al-Hashemi, E., Ashkanani, A., Al-Qattan, H., Mahmoud, A., Al-Kabbani, M., Al-Juhaidli, A., Jaafar, A., \& Al-Hashemi, Z. (2016). Knowledge about epilepsy and attitudes toward students with epilepsy among middle and high school teachers in Kuwait. International Journal of Pediatrics, Volume 2016, Article ID 5138952, 15 pages. doi: http://dx.doi.org/10.1155/2016/5138952.

27. Ghanean, H., Nojomi, M., \& Jacobsson, L. (2013). Public awareness and attitudes towards epilepsy in Tehran, Iran. Global Health Action, 6(1), 21618. doi: 10.3402/gha.v6i0.21618. doi: https://doi.org/10.3402/gha.v6i0.21618.

28. Karimi, N., \& Akbarian, S. A. (2016). Knowledge and attitude toward epilepsy of close family members of people with epilepsy in North of Iran. Advances in Medicine, Volume 2016, Article ID 8672853, 6 pages. doi: http://dx.doi.org/10.1155/2016/8672853. 
29. Falavigna, A., Teles, A. R., Roxo, M. R. R., Velho, M. C., da Silva, R. C., Mazzocchin, T., \& Vedana, V. M. (March, 2009). Awareness and attitudes on epilepsy among undergraduate health care students in Southern Brazil. Journal of Epilepsy Clinical Neurophysiology, 15(1):19-23. doi: http://dx.doi.org/10.1590/S1676-26492009000100005. Retrieved January 20, 2018 from http://www.scielo.br/scielo.php?script=sci_arttext\&pid=S167626492009000100005.

30. Dayapoğlu, N., \&Tan, M. (August, 2016). Clinical nurses' knowledge and attitudes toward patients with epilepsy. Epilepsy and Behaviour, 61: pages 206-209. doi: 10.1016/j.yebeh.2016.05.009.

31. Thapar, A. K. (January, 1996). Care of patient with epilepsy in the community: Will new initiatives address old problems? British Journal of General Practice, 46(402): 37-42. Retrieved January 22, 2018 from http://bjgp.org/content/46/402/37.short.

32. American Society of Registered Nurses. (June 1, 2008). Epilepsy nurse care. The Journal of Nursing, ISSN 1940-6967. Retrieved January 22, 2018 form https://www.asrn.org/journalnursing/373-epilepsy-nurse-care.html.

33. Ridsdale, L., Robins, D., Williams, H., \& Cryer, C. (1997). Feasibility and effects of nurse run clinics for patients with epilepsy in general practice: randomised controlled trial. British Medical Journal, 314: page 120. doi: https://doi.org/10.1136/bmj.314.7074.120.

34. Shehata, G. A., El-Lateef, Z. A., Ghanem, H. M., \& El-Masry, M. A. (2015). Knowledge, attitude and practice regarding people with epilepsy among nurses. Aktualności Neurologiczne, Volume 15, Issue 4: pages 192-198. doi:10.15557/AN.2015.0025.

35. Buelow, J. M., Privitera, M., Levisohn, P., \& Barkley, G. L. (July, 2009). A description of current practice in epilepsy monitoring units. Epilepsy and Behaviour, 15(3): pages 308-13. doi: 10.1016/j.yebeh.2009.04.009.

36. Baskind, R., \& Birbeck, G. (2005). Epilepsy Care in Zambia: A Study of traditional healers. Epilepsia, 46(7): pages 1121-1126. Retrieved February 1, 2018 from http://onlinelibrary.wiley.com/doi/10.1111/j.1528-1167.2005.03505.x/epdf.

37. Tidy, C. (2015). Treatments of epilepsy. Retrieved January 31, 2018 from https://patient.info/health/epilepsy-and-seizures/treatment-for-epilepsy.

38. Sharkawy, G. E., Newton, C., \& Hartley, S. (February, 2006). Attitudes and practices of families and health care personnel toward children with epilepsy in Kilifi, Kenya. Epilepsy and Behaviour, 8(1): pages 201-212. doi: https://doi.org/10.1016/j.yebeh.2005.09.011.

39. Goodman, M. H. (Ed.). (2004). What causes seizures? The triggering factor. New York: Glencoe.

40. Hosseini, N., Sharif, F., Ahmadi, F., \& Zare, M. (2016). Determining the disease management process for epileptic patients: A qualitative study. Iranian Journal of Nursing 
American Journal of Health, Medicine and Nursing Practice

ISSN 2520-4017 (Online)

Vol.5, Issue 1 No.4, pp 43 - 65, 2020

www.ajpojournals.org

and Midwifery Research, 21(1): 54-62. doi:10.4103/1735-9066.174748. PMCID:

PMC4776561.

41. Teferi, J., \& Shewangizaw, Z. (May, 2015). Assessment of knowledge, attitude, and practice related to epilepsy: a community-based study. Neuropsychiatric Disease and Treatment, 11, 1239-1246. doi:10.2147/NDT.S82328.

42. Mustapha, A. F., Odu, O. O., \& Akande, O. (2013). Knowledge, attitudes and perceptions of epilepsy among secondary school teachers in Osogbo South-West Nigeria: A community based study. Nigerian Journal of Clinical Practice, 16(1): pages 12-18. doi:10.4103/11193077.106709.

43. Chomba, E. N., Haworth, A., Atadzhanove, M., Mbewed, E., \& Birbeck, G. L. (February, 2007). Zambian health care workers' knowledge, attitudes, beliefs, and practices regarding epilepsy. Epilepsy and Behaviour, 10(1): pages 111-119. doi:10.1016/j.yebeh.2006.08.012.

44. Ring, H. (2013). Epilepsy in intellectual disabilities. Advances in Clinical Neuroscience and Rehabilitation, 13(5): 14-15.

45. Olotu, V., Shankar, R., \& Bernal, J. (n.d.). Epilepsy. Intellectual Disability and Health. UK: University of Hertfordshire. Retrieved January 20, 2018 from http://www.intellectualdisability.info/physical-health/articles/epilepsy.

46. Jones, B. (1983). Counselling the epileptic patient. Canadian Family Physician, 29: 107111. Retrieved January 30, 2018 from https://www.ncbi.nlm.nih.gov/pmc/articles/PMC2153557/pdf/canfamphys00227-0109.pdf. 